\title{
Breast-feeding duration: influence on taste acceptance over the first year of life
}

\author{
Camille Schwartz ${ }^{1,2,3}+$, Claire Chabanet ${ }^{1,2,3}{\text {, Caroline } \text { Laval }^{1,2,3} \text {, Sylvie Issanchou }}^{1,2,3}$ \\ and Sophie Nicklaus ${ }^{1,2,3 *}$ \\ ${ }^{1}$ INRA, UMR1324 Centre des Sciences du Goût et de l'Alimentation, 17 rue Sully, BP 86510, F-21000 Dijon, France \\ ${ }^{2}$ CNRS, UMR6265, Centre des Sciences du Goût et de l'Alimentation, F-21000 Dijon, France \\ ${ }^{3}$ Université de Bourgogne, Centre des Sciences du Goût et de l'Alimentation, F-21000 Dijon, France
}

(Submitted 22 November 2011 - Final revision received 1 February 2012 - Accepted 4 February 2012 - First published online 4 July 2012)

\begin{abstract}
Early feeding experiences, e.g. related to milk feeding, can affect later food and taste preferences. However, consequences of breast-feeding on taste acceptance are under-investigated. The objective of the present study was to examine the impact of exclusive breast-feeding duration (DEB) on taste acceptance at 6 and 12 months in the same infants ( $n$ 122). Mothers recorded the DEB. Acceptance of solutions of each of the five basic tastes relative to water was evaluated in the laboratory at 6 and 12 months by the ingestion ratio (IR). Kendall correlations were calculated between the DEB and the IR. Only 16\% completed at least 6 months of exclusive breast-feeding; $79 \%$ had begun complementary feeding by 6 months. At 6 months, infants preferred sweet, salty and umami solutions over water and were indifferent to sour and bitter solutions. The longer an infant was breast-fed, the more s/he accepted the umami solution at 6 months. At 12 months, infants preferred sweet and salty solutions over water and were indifferent to sour, bitter and umami solutions. The relationship between the DEB and acceptance of the umami solution was not observed at 12 months. No relationship was observed between the DEB and sweet, salty, sour and bitter taste acceptance at 6 or 12 months. The association between the DEB and umami taste acceptance at 6 months may relate to the higher glutamate content of human milk compared with formula milk. Beyond the acknowledged metabolic benefits of breastfeeding, this suggests that prolonged breast-feeding could also be associated with an impact on sensory preference at the beginning of complementary feeding.
\end{abstract}

Key words: Breast-feeding: Taste: Preference: Imprinting: Infants

According to a growing body of literature, early feeding experiences can have important impact on later food and taste acceptance ${ }^{(1-4)}$, which is one of the major determinants of food consumption in children ${ }^{(5)}$. Among early experiences, those related to milk feeding, whether it is breast-feeding or formula feeding, because they constitute the very first taste experience, could particularly have an impact on later food acceptance ${ }^{(6)}$.

One of the most illustrative examples of this phenomenon is the impact of feeding a hydrolysed protein formula, which is sour- and bitter-tasting ${ }^{(7,8)}$, prescribed in the case of allergy to cows' milk protein, on later preferences. Infants exposed to such a formula during their first 7 months readily accepted it at 7.5 months, whereas it was rejected by non-exposed infants $^{(9)}$. Moreover, a longer exposure to this formula was associated with its higher acceptance at 7.5 months ${ }^{(9)}$. Such exposure has also a long-term impact: a sour apple juice, but not a bitter apple juice, was more accepted by $4-5$-year-old children previously exposed to this hydrolysed protein formula than by non-exposed children ${ }^{(10)}$. This effect was no longer observed at 6-7 years ${ }^{(11)}$.

Nowadays, the beneficial impact of breast-feeding on different functions and, in particular, on the infant's early immunity has become obvious and is recognised through international nutritional policies, which recommend to exclusively breastfeed up until the age of 6 months ${ }^{(12,13)}$. Beyond these metabolic benefits of breast-feeding, and since early feeding experiences are likely to have an impact on later taste and food preferences, it is also important to understand better the sensory impact of breast-feeding ${ }^{(6)}$. Compared with exposure to formula, exposure to maternal milk may result in sensory difference in terms of aroma and taste. Concerning aroma, some volatile compounds from the foods ingested by the mother are likely to be transmitted into her milk ${ }^{(14,15)}$. Thus, breast milk may bear a distinct flavour component which is likely to have an

Abbreviations: DEB, duration of exclusive breast-feeding; IR, ingestion ratio; OPALINE, Observatory of Food Preferences in Infants and Children.

*Corresponding author: S. Nicklaus, fax +33 3806932 27, email sophie.nicklaus@dijon.inra.fr

† Present address: Biopsychology Group, Institute of Psychological Sciences, University of Leeds, Leeds LS2 9JT, UK. 
impact on infant behaviour at the age of complementary feeding (about 6 months), as has been shown in several studies ${ }^{(6,16,17)}$. Concerning taste, breast milk contains some compounds which bear a taste, such as lactose (sweet taste), glutamate (umami taste), $\mathrm{Na}$ (salty taste) and urea (bitter taste) ${ }^{(18)}$. Their concentration in breast milk may differ from that in formula milks: the concentration of glutamate is 14-fold higher, but the concentration of $\mathrm{Na}$ is 2 - to 4 -fold lower ${ }^{(19-21)}$. The impact of breast-feeding on later taste acceptance has been rarely assessed. A recent study indicated that breast-fed infants did not differ from infants fed a milk-based formula in their intake of cereals prepared with sweet, salty, sour, bitter and umami solutions, but they displayed more positive facial responses to umami-based cereals ${ }^{(22)}$. This may relate to a higher exposure to glutamate in breast milk compared with formula milks. Another study has revealed that the longer 16- to 25-week-old infants were breast-fed, the less they accepted their first salted cereals over plain cereals ${ }^{(23)}$. This was interpreted in relation to the low $\mathrm{Na}$ content of breast milk. The present study aimed at examining the impact of exclusive breast-feeding duration (DEB) on the acceptance of sweet, salty, sour, bitter and umami taste solutions at 6 and 12 months. Since breast milk has higher glutamate content than formula milks, we hypothesised that the longer an infant was breast-fed, the more s/he would be exposed to umami taste and thus the more $\mathrm{s} /$ he would accept umami taste. Similarly, because formula milk can contain up to twice as much $\mathrm{Na}$ as breast milk, breast-feeding could result in a diet lower in $\mathrm{Na}^{(24)}$, thus we hypothesised that the longer an infant was breast-fed, the less $\mathrm{s} /$ he would accept salty taste. We did not expect to observe an effect of DEB on the acceptance of sweet, sour and bitter tastes.

\section{Subjects}

The present study was part of the OPALINE programme (Observatory of Food Preferences in Infants and Children) aimed at understanding the formation of food preferences from birth until the age of 2 years. Participating mothers were recruited before the last trimester of pregnancy with the help of doctors, paediatricians, midwives, pharmacists and day-care centre staff. To be included in the study, parents had to have reached legal majority and infants had to be in good health at birth. Data from 137 infants were considered but infants fed a mixed formula and breast milk diet from birth on $(n 10)$ were excluded from the present study because of non-exclusivity of breast milk feeding. Infants fed hydrolysed protein formula ( $n$ 5) were also excluded because this experience is associated with a very specific taste acceptance profile ${ }^{(22)}$. Here data are reported for 122 infants (sixty-two males), with a birth weight of 3.31 (SD 0.51$) \mathrm{kg}$ and a length at birth of $50.0(\mathrm{SD} 2.4) \mathrm{cm}$. The accompanying parent was usually the mother. The present study was conducted according to the guidelines laid down in the Declaration of Helsinki and all procedures involving parents and infants were approved by the CPP (Comité de Protection des Personnes) Est I Bourgogne. Written informed consent was obtained from both parents for all infants. Mother inclusion started in June 2005 and taste acceptance sessions were performed between July 2006 and September 2009.

\section{Methods}

\section{Infant feeding history including breast-feeding history}

From the birth of their infant on, the mothers were asked each month over the first year to fill in a $7 \mathrm{~d}$ food diary aimed at describing accurately the infant milk and solid feeding experience. In particular, they specified whether they exclusively breast-fed their infant (i.e. with no other milk and no other food) and, if so, the date when they stopped to do so. They also specified which type of formula milk their infant was fed over the first year, and when they started to introduce complementary foods. The DEB was calculated as the difference between the delivery date and the date when any food other than breast milk was introduced into the infant's diet. The age at the beginning of complementary feeding was calculated as the difference between the delivery date and the date when any food other than milk (breast or formula) was introduced.

\section{Taste acceptance procedure}

The taste acceptance procedure, adapted from previously proposed methods ${ }^{(25,26)}$, has been fully described elsewhere ${ }^{(27)}$. Infant taste acceptance was assessed at the corrected ages of 6 and 12 months (i.e. age considering the calculated delivery date, not the actual delivery date).

For each taste, a solution was prepared using mineral water $\left(\right.$ Evian $^{\circledR}$ ) and food-pharmacological-grade compounds (Jerafrance). The compounds chosen to represent each taste could have been encountered by infants in amniotic fluid or in their diet either in breast/formula milk or in solid food ${ }^{(18,28-30)}$ (Table 1). The concentrations were determined to be above adult detection thresholds, since infant detection thresholds might be in the same range as those of adults ${ }^{(31)}$, and to generate moderate intensities in order to avoid stereotypical reactions observed in some studies using high concentrations ${ }^{(32)}$. Sensory tests conducted with an adult panel (results not reported) confirmed that these supra-threshold concentrations generated perceptions of moderate intensities. At each age, infants participated in two videotaped sessions at approximately the same time of the day. Parents were asked not to feed their infant during the hour before the test session. For each taste, a fixed sequence of four bottles 'water-tastant-tastant-water' was presented to the infant by the experimenter. Within a sequence, each bottle was presented for $45 \mathrm{~s}$ with a $15 \mathrm{~s}$ pause between the bottles. Between two sequences, for all infants, a pause of at least $1 \mathrm{~min}$ was allowed. The five sequences corresponding to the five tastes were presented in a double-blind balanced

Table 1. Compound and concentration used for the preparation of each taste solution

\begin{tabular}{llc}
\hline Taste & Compound & Concentration (M) \\
\hline Sweet & Lactose & 0.20 \\
Salty & NaCl & 0.085 \\
Sour & Citric acid & 0.006 \\
Bitter & Urea & 0.18 \\
Umami & Monosodium glutamate & 0.009 \\
\hline
\end{tabular}


order, over the two sessions. The mother and the experimenter wore a mask during all sequences to prevent any influence from their facial expressions ${ }^{(22)}$. To determine ingestion, bottles were weighed before and after consumption. Analysis was restricted to infants who met the ingestion criteria, i.e. who consumed at least $1.0 \mathrm{~g}$ from two bottles over a sequence. The ingestion ratio (IR) of a taste was defined as the ingested volume of this taste solution relative to the sum of the ingested volumes of this taste solution and of water. This IR varies by definition between 0 and 1 . It can be interpreted as the following: 0.5 indicates indifference to the taste solution; ratio above 0.5 indicates a preference for the taste solution over water; ratio below 0.5 indicates a rejection of the taste solution over water.

\section{Statistical analyses}

Statistical analyses were carried out using $\mathrm{R}$ version $\mathrm{R} 2.8 .0$ (R Foundation for Statistical Computing; http://www.R-project. org). For infants who were not exclusively breast-fed at birth, the DEB was set at 0 . For the analysis at 6 months, the DEB was truncated to $183 \mathrm{~d}(6$ months $\times 30 \cdot 5 \mathrm{~d})$. For each age and each taste, a Student's $t$ test $\left(t_{\mathrm{df}=n-1}\right)$ was used to assess whether the IR was different from 0.5 and thus whether the taste was preferred or rejected over water. A paired Student's $t$ test $\left(t_{\mathrm{df}=n-1}\right)$ was also computed to evaluate whether taste acceptance differed between the ages of 6 and 12 months. Moreover, for each age and each taste, a Kendall correlation $\left(\tau_{\mathrm{df}=n-2}\right)$ was calculated between the DEB and the IR. The significance criterion was set at $0 \cdot 05$. Results are expressed as means and standard deviations.

For each age and each taste, ANCOVA models were performed to evaluate the effect on taste acceptance (IR) of DEB and of the following covariates: sex; the difference between the expected and real birth date; duration since the introduction of complementary feeding. The results of these analyses were not reported since none of the covariates had a significant effect $(P>0 \cdot 05)$.

\section{Results}

\section{Subjects' characteristics}

The mothers were $31 \cdot 3$ (SD $4 \cdot 1$ ) years old on average and their average BMI was 22.2 ( $\mathrm{sD} 3.4) \mathrm{kg} / \mathrm{m}^{2}$. Of the subjects, half were primiparous $(50 \%)$. A minority of the mothers gave birth by caesarean section (17\%).

\section{Breast-feeding and solid feeding practices}

The present analysis was focused on infants who either received no breast-feeding from birth on $(13 \%)$ or exclusive breastfeeding (87\%). The DEB was widely distributed: first quartile, $38 \mathrm{~d}$; median, $103 \mathrm{~d}$; third quartile, $154 \mathrm{~d}$. Of the mothers who participated in the study, twenty (16\%) completed 6 months of exclusive breast-feeding. At the age of 12 months, none of the mothers was exclusively breast-feeding.
The age at the beginning of complementary feeding was not as variable as the DEB: first quartile, $144 \mathrm{~d}$; median, $169 \mathrm{~d}$; third quartile, $183 \mathrm{~d}$. For $79 \%$ of the infants, complementary feeding started before the first test session at the age of 6 months: for them, the median duration of complementary feeding was $33 \mathrm{~d}$ (first quartile, $14 \mathrm{~d}$; third quartile, $54 \mathrm{~d}$ ). At the age of 12 months, all infants were fed a solid diet, and the median duration of complementary feeding was $204 \mathrm{~d}$ (first quartile, $183 \mathrm{~d}$; third quartile, $226 \mathrm{~d}$ ).

\section{Taste acceptance at 6 and 12 months}

For some infants, IR data were missing for some specific tastes but all available IR were included in the analyses. Missing IR data happened for several reasons. First, some infants could not participate in a specific measurement session (resulting in a loss of six to eleven cases at the age 6 months and of sixteen to twenty-two cases at the age of 12 months). Second, some infants did not comply with the experimental procedure by refusing to drink from a bottle (two cases at the age of 6 months and three cases at the age of 12 months). Third, some infants did not complete the four-bottle sequence or did not meet the ingestion criteria (between one and nine cases at the age of 6 months and between two and seven cases at the age of 12 months).

Infants were first seen at the average age of 191 (SD 14) d (corrected age 181 (SD 8) d). The test sessions took place 130 (SD 49) min after the infant's last meal. On average, infants weighed $7 \cdot 4(\mathrm{SD} 0 \cdot 8) \mathrm{kg}$ and were $66.2(\mathrm{SD} 5 \cdot 9) \mathrm{cm}$ long. At the age of 6 months, on average infants preferred sweet (IR 0.58 (SD 0.14); $\left.t_{106}=5.72 ; P<0.0001\right)$, salty (IR 0.55 (SD 0.11); $\left.t_{110}=5.01 ; \quad P<0.0001\right)$ and umami (IR 0.53 (SD $0 \cdot 11$ ); $\left.t_{105}=3.00 ; P=0.0034\right)$ tastes over water. They were indifferent to sour and bitter tastes compared with water (IR 0.50 (SD 0.13 ); $t_{108}=0.36 ; P=0.72 ;$ IR 0.49 (SD 0.09); $t_{105}=-1.54$; $P=0 \cdot 13$, respectively).

For the taste acceptance assessment at the age of 12 months, infants were 371 (SD 15) d old (corrected age 362 (SD 8) d). The test sessions took place 129 (SD 53) $\mathrm{min}$ after the infant's last meal. On average, infants weighed 9.5 (SD 1.0) kg and were 74.6 (sD 2.9) $\mathrm{cm}$ long. At the age of 12 months, on average infants preferred sweet (IR 0.61 (SD 0.18); $\left.t_{98}=6.04 ; P<0.0001\right)$ and salty (IR 0.59 (SD 0.15); $\left.t_{96}=5.47 ; P<0.0001\right)$ tastes over water. They were indifferent to sour, bitter and umami tastes compared with water (IR 0.50 (SD 0.17); $t_{91}=0.09 ; P=0.93$; IR 0.48 (SD 0.12); $t_{99}=-1 \cdot 29 ; P=0.20 ;$ IR 0.50 (SD 0.16); $t_{94}=0 \cdot 29 ; P=0 \cdot 77$, respectively).

Paired $t$ tests contrasting acceptance at 12 months and acceptance at 6 months did not reveal evolution with age for any taste: sweet taste $\left(t_{87}=1.61 ; P=0.11\right.$; salty taste, $t_{90}=1.82 ; \quad P=0.07 ;$ sour taste, $t_{82}=-0.52 ; \quad P=0.60 ;$ bitter taste, $t_{89}=-0.66 ; P=0.51$; umami taste, $t_{85}=-1.59 ; P=0 \cdot 11$ ).

\section{Impact of the duration of exclusive breast-feeding on taste acceptance}

At the age of 6 months, a positive correlation was observed between the DEB and umami taste acceptance $\left(\tau_{104}=0 \cdot 16\right.$; 
(a)

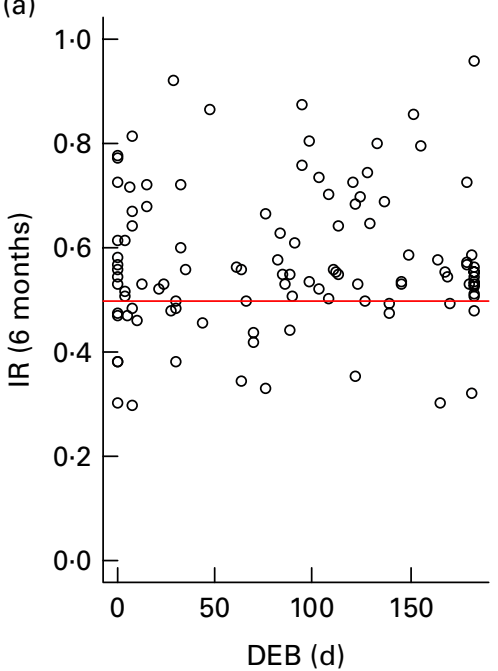

(d)

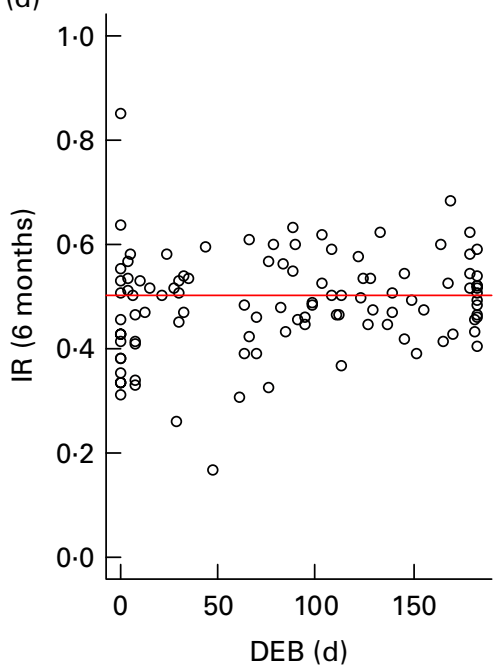

(b)

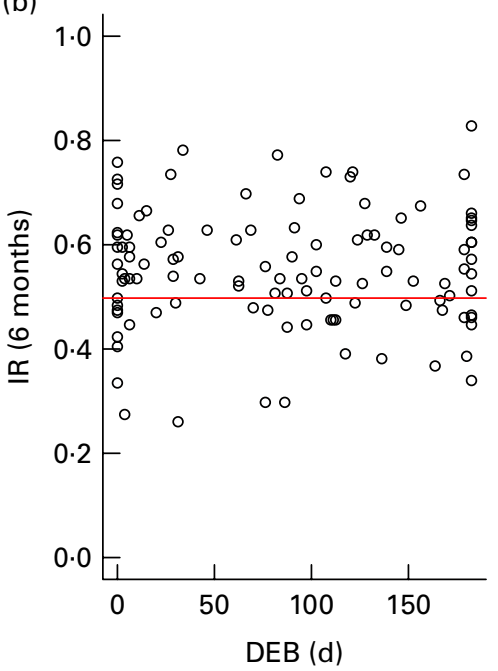

(e)

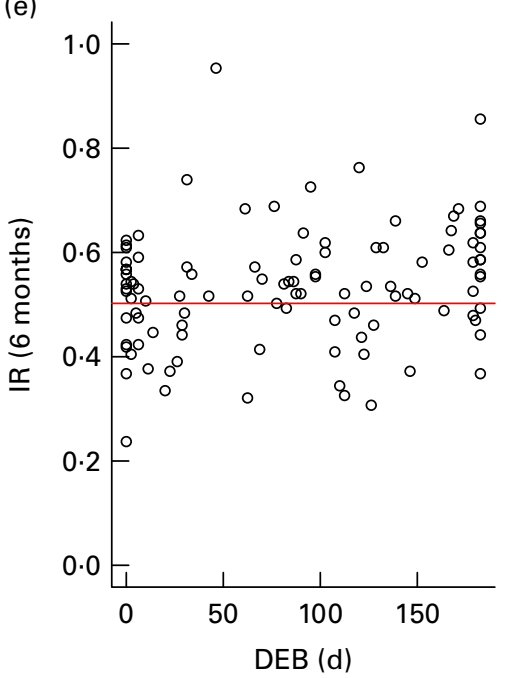

(c)

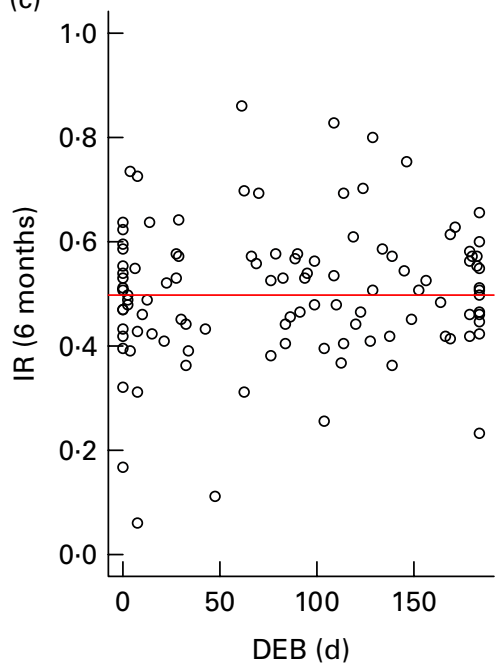

Fig. 1. Scatter plots of acceptance (ingestion ratio (IR)) at the age of 6 months of (a) sweet $(n$ 107), (b) salty $(n$ 111), (c) sour $(n$ 109), (d) bitter ( $n$ 106) and (e) umami ( $n$ 106) taste solutions against duration of exclusive breast-feeding (DEB), and associated Kendall correlations ((a) $\tau=0.04$, (b) $\tau=-0.02$, (c) $\tau=0.05$, (d) $\tau=0.12$ and (e) $\tau=0.16$ ) and $P$ values ((a) $P=0.54$, (b) $P=0.77$, (c) $P=0.47$, (d) $P=0.06$ and (e) $P=0.02$ ). (A colour version of this figure can be found online at http://www.journals.cambridge.org/bjn)

$P=0.02$; Fig. 1). No correlation was observed between the DEB and salty taste acceptance $\left(\tau_{109}=-0.02 ; P=0.77\right)$. As it was hypothesised, no correlation was observed between the DEB and the acceptance of sweet, bitter or sour tastes (sweet taste: $\tau_{105}=0.04 ; P=0.54 ;$ sour taste: $\tau_{107}=0.05$; $P=0 \cdot 47$; bitter taste: $\tau_{104}=0 \cdot 12 ; P=0.06$ )

At the age of 12 months, no significant correlation was observed between the DEB and taste acceptance (sweet taste: $\tau_{97}=-0.02 ; P=0.82 ;$ salty taste: $\tau_{95}=0.05 ; P=0.50$; sour taste: $\tau_{90}=-0.13 ; P=0.07 ;$ bitter taste: $\tau_{98}=-0.04$; $P=0.55$; umami taste: $\tau_{93}=-0.01 ; P=0.87$; Fig. 2 ).

\section{Discussion}

The present study examined the impact of the DEB on taste acceptance at 6 and 12 months. At 6 months, as expected, longer exclusive breast-feeding had a positive impact on umami taste acceptance. This relationship was no longer observed at 12 months. No relationship was observed for salty taste at 6 or 12 months. Finally, with respect to our hypothesis, no correlation was observed between the DEB and sweet, sour and bitter taste acceptance at 6 or 12 months; however, two correlations approached significance: one positive between bitter taste acceptance at 6 months and DEB and one negative between sour taste acceptance at 12 months and DEB. At 6 months, infants preferred sweet, salty and umami solutions over water and were indifferent to sour and bitter solutions. At 12 months, infants preferred sweet and salty solutions over water and were indifferent to sour, bitter and umami solutions. The effects of some covariates (sex, difference between the expected and real birth date, duration since the introduction of complementary feeding) on the acceptance of basic tastes were considered in ANCOVA. However, none of any of the studied covariates 

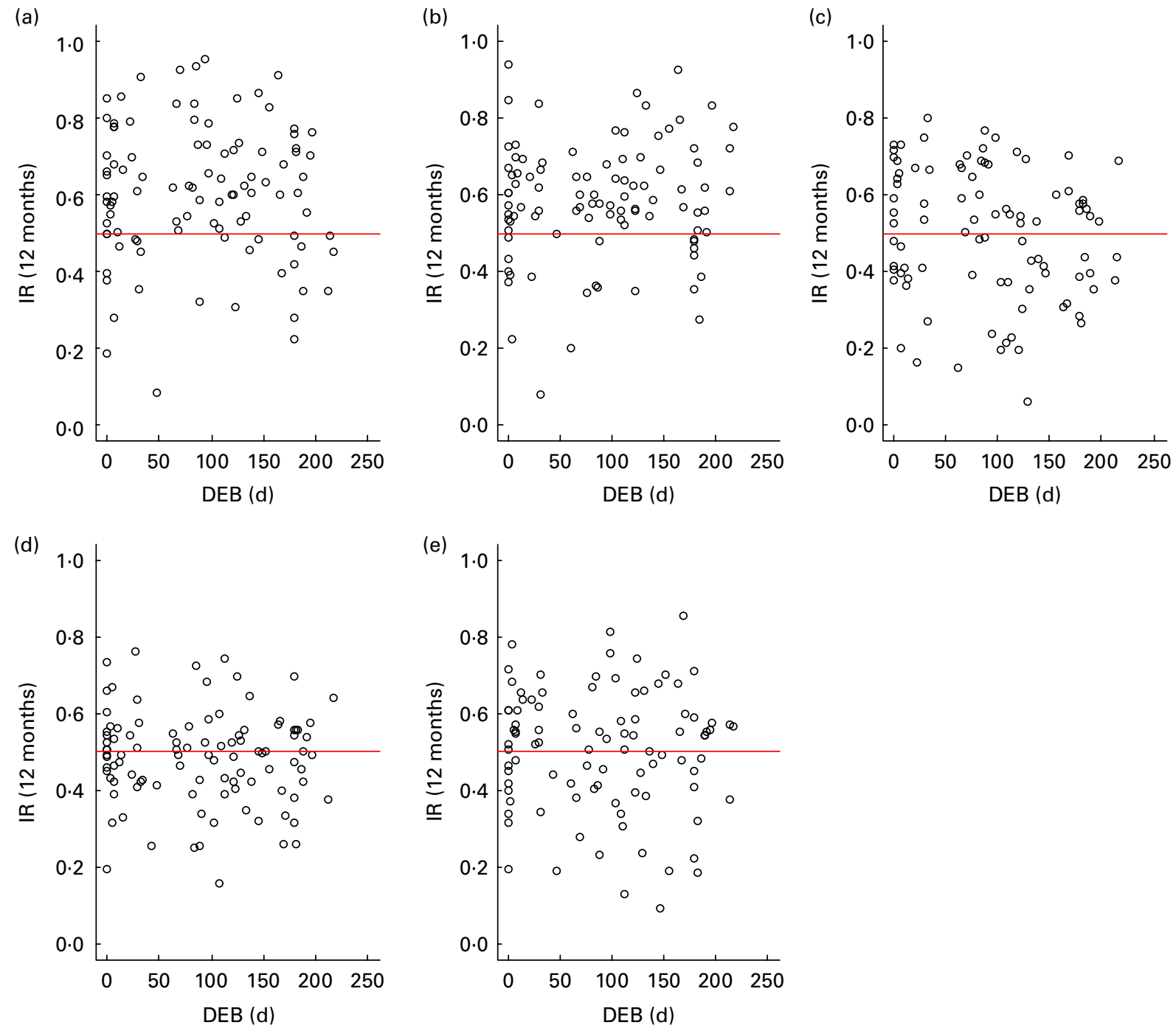

Fig. 2. Scatter plots of acceptance (ingestion ratio (IR)) at the age of 12 months of (a) sweet $(n$ 99), (b) salty ( $n$ 97), (c) sour ( $n$ 92), (d) bitter ( $n$ 100) and (e) umami ( $n$ 95) taste solutions against duration of exclusive breast-feeding (DEB), and associated Kendall correlations $((\mathrm{a}) \tau=-0.02$, (b) $\tau=0.05$, (c) $\tau=-0.13$, (d) $\tau=-0.04$ and (e) $\tau=-0.01$ ) and $P$ values ((a) $P=0.82$, (b) $P=0.05$, (c) $P=0.07$, (d) $P=0.55$ and (e) $P=0.87$ ). (A colour version of this figure can be found online at http://www.journals.cambridge.org/bjn)

had any effect on taste acceptance, for any age and any taste when taking into account, in the same model, the role of the DEB.

The observed association between the DEB and umami taste preference at 6 months, studied using monosodium glutamate, might be related to the effect of exposure to glutamate in breast milk as hypothesised. First, this association was modest. This might result from the variability in infant's behaviour in the taste acceptance measurement, or from the variability in infant's exposure to other foods. One might not exclude that introduction of complementary feeding could have an impact on taste acceptance ${ }^{(22)}$; however, the present analysis did not reveal an effect of the duration since the beginning of complementary feeding. Second, the interpretation of the present findings is limited by the fact that breast milk was neither analysed for taste compound composition, nor evaluated by a sensory panel to characterise its perceived taste. Thus, the exposure effect might only be interpreted in the light of previous findings. The possibility of an 'imprinting' effect of early exposure to glutamate in breast milk on the acceptance of umami flavour was previously raised on the basis of animal studies ${ }^{(33,34)}$. In 6-month-old human infants, an effect of exposure to different types of milk on taste acceptance has been shown ${ }^{(22)}$. Infants fed a hydrolysed casein formula, rich in amino acids, consumed more plain, umami-, bitter- or sour-tasting cereals than breast-fed infants or infants fed a regular formula. Infants fed a hydrolysed casein formula and breast-fed infants were more likely to smile when eating the umami-tasting cereal than infants fed a regular formula. These results were discussed in relation to the imprinting role of exposure to hydrolysed casein formula on further taste acceptance. Similarly, here, the 14-fold higher glutamate content in breast milk compared with that in formula milk ${ }^{(19)}$ might have led to a higher exposure to umami taste in breast-fed infants, resulting at 6 months in a higher acceptance of a umami solution prepared 
with monosodium glutamate. The $1.18 \mathrm{mmol} / 1$ glutamate content of breast milk ${ }^{(19)}$ is above the adult glutamate detection threshold, comprised between 0.08 and $0.39 \mathrm{mmol} / \mathrm{l}^{(35)}$, and might result in a direct sensory exposure. The glutamate content in breast milk increases over the first trimester of lactation $^{(18,28)}$, and is relatively stable thereafter ${ }^{(36)}$. This increase might be associated with the preference for umami taste at 6 months. The stability of breast milk glutamate content after 6 months and the progressive cessation of exclusive breastfeeding and initiation of complementary feeding in the second part of the first year ${ }^{(37)}$ might explain the absence of an association between breast-feeding duration and umami taste acceptance at 12 months. Altogether, the impact of exclusive breast-feeding on umami taste acceptance seems to be transient. It was observed at an age close to the beginning of complementary feeding and could favour the initial acceptance of umami-tasting foods with limited longer-term effect.

This could constitute a 'taste bridge' effect, in the same way that a 'flavour bridge' effect was previously described by Mennella and collaborators ${ }^{(6,16)}$ regarding flavour transition from breast milk to a solid diet. We showed elsewhere that between 5 and 7 months, the period corresponding to the beginning of complementary feeding, the more an infant liked umami, sweet or sour tastes, the more $\mathrm{s} /$ he accepted some of the foods bearing these tastes ${ }^{(38)}$. It was speculated that the attraction to umami taste could derive from a specific ability to detect the presence of amino acids and proteins, which would be specifically efficient in protein- or aminoacid-deprived organisms. This was confirmed in amino acid-deficient animals ${ }^{(34)}$ but not in malnourished infants ${ }^{(39)}$. In healthy adults, taste threshold for monosodium glutamate combined with inosine $5^{\prime}$-monophosphate was found to be correlated with a liking for protein-rich foods ${ }^{(40)}$. Therefore, the high glutamate content in breast milk may reflect a specific need for amino acids in primate infants ${ }^{(41,42)}$, and in this view, the increased acceptance of umami taste following exclusive breast-feeding could be considered as a remarkable adaptation to guide the body towards foods bearing a specific nutritional function such as amino acids ${ }^{(43)}$. However, the specific role of glutamate in foods at this developmental stage remains to be elucidated. In this perspective, the metabolic role of glutamate in early development needs to be clarified, in particular its consequences on enteral functions ${ }^{(19,44)}$.

The slight preference (IR 0.53) for the glutamate solution compared with water at 6 months might seem surprising. Glutamate acceptance depends on the vehicle and on the concentration: in 3-24-month-old infants, adding $0 \cdot 20$ or $0.40 \%$ glutamate to water reduced its ingestion, but not 0.05 or $0 \cdot 10 \%{ }^{(45)}$, whereas adding glutamate to a vegetable soup increased its ingestion ${ }^{(39)}$. Adding glutamate to cereals did not have an impact on intake in 6-month-old formula- or breast-fed infants ${ }^{(22)}$. In line with the present slight preference for $0.17 \%$ glutamate in water in 6-month-old infants and indifference in 12-month-old infants, one might consider the hypothesis of a concentration- and age-dependent preference for glutamate water solution.

Concerning salty taste, the present results did not corroborate previous findings ${ }^{(23)}$. The $\mathrm{Na}$ content of formula milks is about 2-fold higher than that of breast milk, whereas glutamate content in breast milk is 14-fold higher than in formula milks. This discrepancy could explain that the limited difference in exposure to salt resulting from longer breast-feeding did not result in a modified salt taste acceptance. Because most of the infants had already been receiving complementary foods by 6 months, any earlier difference in salt intake between formula- and breast-fed infants could have become blurred by this age.

The absence of the rejection of sour and bitter solutions might seem surprising. The possibility that some stimuli were not detected by some infants cannot be ruled out. However, infants exhibited negative facial expressions while drinking bitter and sour solutions (not reported here but discussed elsewhere $\left.{ }^{(27,46)}\right)$. Negative expressions and ingestion have also been reported in newborns tasting a urea solution $^{(32,47,48)}$. Adding citric acid to a mildly sweet solution was associated with a reduced ingestion in 2-24-month-old infants ${ }^{(39)}$ but not its addition to water in newborns ${ }^{(48)}$. Moreover, in 6-month-old infants, $0 \cdot 24 \mathrm{M}$-urea addition to cereals was not associated with a clear decrease in intake compared with plain cereal, neither was $0.006 \mathrm{M}$-citric acid addition ${ }^{(22)}$ Therefore, bitter and sour taste rejections do not seem to be systematic in infants.

A specific limitation to any study on breast-feeding is that it is not possible to carry out interventional studies randomising breast-feeding. Rate and duration of breast-feeding may vary according to several factors, in particular the mother's social status $^{(49,50)}$. The observed effect of breast-feeding could be confounded with other factors related to the mother such as education. Here, such factors are unlikely to have directly affected the infant's behaviour during the sessions since taste acceptance was assessed using a double-blind procedure in which stimuli were delivered by the experimenter, not by the mother, and the outcome measure, the IR, was independent from the mother's judgement. To understand better the sensory consequences of exposure to breast milk, future studies on the development of taste and food preferences should focus on the analysis of breast milk composition, which has not been conducted here.

The present study highlighted the role of exclusive breastfeeding in the establishment of taste acceptance: longer exclusive breast-feeding has a positive impact on umami taste acceptance at the age of 6 months. Future studies should follow on studying the impact of breast-feeding on infants acceptance of protein-rich foods such as meat, fish or cheese, or of foods such as tomatoes, mushrooms or peas in which glutamate content is higher than that of breast milk $^{(51)}$, as well as the nutritional benefits of such foods at this age. Moreover, the sensory, behavioural and metabolic consequences of higher glutamate exposure in breast-fed infants deserve further exploration.

\section{Acknowledgements}

This study was funded by grants of the Regional Council of Burgundy, of IFR92, of the Nutrition, Chemical Food Safety and Consumer Behaviour Division of INRA, of 
PRNH-INRA-INSERM, of the ANR (The French National Research Agency) under the Programme National de Recherche en Alimentation et nutrition humaine, project ANR-06PNRA-028, OPALINE; of the Benjamin Delessert Institute (Prix de Recherche 2008 to C. S.) and of the food-related companies Blédina, Nestlé, Symrise, CEDUS and Valrhona. The authors wish to thank the participating infants and parents; and the study experimenters: E. Szleper, J. Pierard and V. Feyen. The OPALINE team, in particular P. Schlich, C. Lange and S. Monnery-Patris, are thanked for their continuing support. C. S. designed the method, collected the sensory data and wrote the paper. C. C. analysed the data and contributed to the writing of the paper. C. L. recruited the subjects, collected the background data and organised the appointments. S. I. designed the method and wrote the paper. S. N. designed the method, collected the grant and wrote the paper. None of the authors has any conflict of interest to report.

\section{References}

1. Beauchamp GK \& Mennella JA (2008) Early flavor learning and its impact on later feeding behavior. J Pediatr Gastroenterol Nutr 48, Suppl. 1, S25-S30.

2. Cooke L (2007) The importance of exposure for healthy eating in childhood: a review. J Hum Nutr Diet 20, 294-301.

3. Harris G (2008) Development of taste and food preferences in children. Curr Opin Clin Nutr Metab Care 11, 315-319.

4. Nicklaus S (2009) Development of food variety in children. Appetite 52, 253-255.

5. Nicklaus S \& Issanchou S (2007) Children and food choice. In Understanding Consumers of Food Products, pp. 329-358 [L Frewer and H van Trijp, editors]. Cambridge: Woodhead Publishing Limited.

6. Mennella JA (2009) Flavour programming during breastfeeding. Adv Exp Med Biol 639, 113-120.

7. Arai S (1980) The bitter flavor due to peptides or protein hydrolysates and its control by bitterness-masking with acidic oligopeptides. In The Analysis and Control of Less Desirable Flavors in Food and Beverages, pp. 133-147 [G Charalambous, editor]. New York, NY: Academic Press.

8. Pedrosa M, Pascual CY, Larco JI, et al. (2006) Palatability of hydrolysates and other substitution formulas for cow's milk-allergic children: a comparative study of taste, smell, and texture evaluated by healthy volunteers. I Investig Allergol Clin Immunol 16, 351-356.

9. Mennella JA, Griffin CE \& Beauchamp GK (2004) Flavor programming during infancy. Pediatrics 113, 840-845.

10. Mennella JA \& Beauchamp GK (2002) Flavor experiences during formula feeding are related to preferences during childhood. Early Hum Dev 68, 71-82.

11. Liem DG \& Mennella JA (2002) Sweet and sour preferences during childhood: role of early experiences. Dev Psychobiol 41, 388-395.

12. World Health Organization (2001) Report of the Expert Consultation of the Optimal Duration of Exclusive Breastfeeding. Geneva: WHO.

13. World Health Organization (2003) Feeding and Nutrition of Infants and Young Children. Guidelines for the WHO European Region, with Emphasis on the Former Soviet Countries. no. 87. Geneva: WHO.

14. Mennella JA \& Beauchamp GK (1991) Maternal diet alters the sensory qualities of human milk and the nursling's behavior. Pediatrics 88, 737-744.
15. Hausner H, Bredie WLP, Mølgaard C, et al. (2008) Differential transfer of dietary flavour compounds into human breast milk. Physiol Behav 95, 118-124.

16. Mennella JA, Jagnow CP \& Beauchamp GK (2001) Prenatal and postnatal flavor learning by human infants. Pediatrics 107, e88.

17. Hausner H, Nicklaus S, Issanchou S, et al. (2010) Breastfeeding facilitates acceptance of a novel dietary flavour compound. Clin Nutr 29, 141-148.

18. Jensen RG (1995) Handbook of Milk Composition. New York, NY: Academic Press

19. Agostoni C, Carratu B, Boniglia C, et al. (2000) Free amino acid content in standard infant formulas: comparison with human milk. J Am Coll Nutr 19, 434-438.

20. Neville MC, Allen JC, Archer PC, et al. (1991) Studies in human lactation: milk volume and nutrient composition during weaning and lactogenesis. Am J Clin Nutr 54, 81-92.

21. Alles MS, Scholtens PAMJ \& Bindels JG (2004) Current trends in the composition of infant milk formulas. Curr Paediatr 14, 51-63.

22. Mennella JA, Forestell CA, Morgan LK, et al. (2009) Early milk feeding influences taste acceptance and liking during infancy. Am J Clin Nutr 90, 780S-788S.

23. Harris G, Thomas A \& Booth DA (1990) Development of salt taste in infancy. Dev Psychol 26, 534-538.

24. Mosser F (2005) Le sel: vigilance dans la première année de vie (Salt: watchfulness during the first year of life). Cah Nutr Diet 40, 202-206.

25. Beauchamp GK \& Moran M (1982) Dietary experience and sweet taste preferences in human infants. Appetite 3, 139-152.

26. Beauchamp GK, Cowart BJ \& Moran M (1986) Developmental changes in salt acceptability in human infants. Dev Psychobiol 19, 17-25.

27. Schwartz C, Issanchou S \& Nicklaus S (2009) Developmental changes in the acceptance of the five basic tastes in the first year of life. Br J Nutr 102, 1375-1385.

28. Agostoni C, Carratu B, Boniglia C, et al. (2000) Free glutamine and glutamic acid increase in human milk through a three-month lactation period. J Pediatr Gastroenterol Nutr 31, 508-512.

29. Allen JC, Keller RP, Archer P, et al. (1991) Studies in human lactation: milk composition and daily secretion rates of macronutrients in the first year of lactation. Am J Clin Nutr 54, 69-80.

30. Muller F, Dommergues M, Bussières L, et al. (1996) Development of human renal function: reference intervals for 10 biochemical markers in fetal urine. Clin Chem 42, 1855-1860.

31. Cowart BJ (1981) Development of taste perception in humans: sensitivity and preference throughout the life span. Psychol Bull 90, 43-73.

32. Steiner JE (1979) Human facial expressions in response to taste and smell stimulation. Adv Child Dev Behav 13, $257-295$.

33. Mori M, Kawada T, Ono T, et al. (1991) Taste preference and protein nutrition and L-amino acid homeostasis in male Sprague-Dawley rats. Physiol Behav 49, 987-995.

34. Bellisle F (1999) Glutamate and the umami taste: sensory, metabolic, nutritional and behavioural considerations. A review of the literature published in the last 10 years. Neurosci Biobehav Rev 23, 423-438.

35. Lugaz O, Pillias AM \& Faurion A (2002) A new specific ageusia: some humans cannot taste L-glutamate. Chem Senses 27, 105-115. 
36. Yamawaki N, Yamada M, Kan-no T, et al. (2005) Macronutrient, mineral and trace element composition of breast milk from Japanese women. J Trace Elem Med Biol 19, 171-181.

37. Schwartz C, Chabanet C, Boggio V, et al. (2010) À quelles saveurs les nourrissons sont-ils exposés dans la première année de vie? (To which tastes are infants exposed during the first year of life?). Arch Pediatr 17, 1026-1034.

38. Schwartz C, Chabanet C, Lange C, et al. (2011) The role of taste in food acceptance at the beginning of complementary feeding. Physiol Behav 104, 646-652.

39. Vasquez M, Pearson PB \& Beauchamp GK (1982) Flavor preferences in malnourished Mexican infants. Physiol Behav 28, 513-519.

40. Luscombe-Marsh ND, Smeets A \& Westerterp-Plantenga MS (2008) Taste sensitivity for monosodium glutamate and an increased liking of dietary protein. Br J Nutr 99, 904-908.

41. Ramirez I, DeSantiago S, Tovar AR, et al. (2001) Amino acid intake during lactation and amino acids of plasma and human milk. Adv Exp Med Biol 501, 415-421.

42. Sarwar G, Botting HG, Davis TA, et al. (1998) Free amino acids in milks of human subjects, other primates and nonprimates. Br J Nutr 79, 129-131.

43. Jinap S \& Hajeb P (2010) Glutamate. Its applications in food and contribution to health. Appetite 55, 1-10.
44. Blachier F, Boutry C, Bos C, et al. (2009) Metabolism and functions of L-glutamate in the epithelial cells of the small and large intestines. Am J Clin Nutr 90, 814S-821S.

45. Beauchamp GK \& Pearson P (1991) Human development and umami taste. Physiol Behav 49, 1009-1012.

46. Schwartz C, Issanchou S \& Nicklaus S (2009) Acceptance of bitter and sour tastes in 6-month-old infants: what can we learn from their facial mimics? In 14th European Conference on Developmental Psychology. Vilnius: Mykolas Romeris University.

47. Ganchrow JR, Steiner JE \& Daher M (1983) Neonatal facial expressions in response to different qualities and intensities of gustatory stimuli. Infant Behav Dev 6, 473-484.

48. Desor JA, Maller O \& Andrews K (1975) Ingestive responses of human newborns to salty, sour, and bitter stimuli. J Comp Physiol Psychol 89, 966-970.

49. Gojard S (1998) L'allaitement: une pratique socialement différenciée (Breastfeeding: a socially differentiated practice). Rech Prev 53, 23-34.

50. Li R, Darling N, Maurice E, et al. (2005) Breastfeeding rates in the United States by characteristics of the child, mother, or family: the 2002 National Immunization Survey. Pediatrics 115, e31-e37.

51. Ninomiya K (1998) Natural occurrence. Food Rev Int $\mathbf{1 4}$ $177-211$ 